\title{
Spatial Analysis of Human Health Risk Associated with Trihalomethanes in Drinking Water: A Case Study of Karachi, Pakistan
}

\author{
Zahida Karim, Bilal Aslam Qureshi, and Ishtiaq Ghouri \\ Department of Chemistry, University of Karachi, Karachi 75270, Pakistan \\ Correspondence should be addressed to Zahida Karim; zahidakarim@hotmail.com
}

Received 26 June 2012; Revised 8 September 2012; Accepted 24 September 2012

Academic Editor: Prabhakar Sripadi

Copyright (C) 2013 Zahida Karim et al. This is an open access article distributed under the Creative Commons Attribution License, which permits unrestricted use, distribution, and reproduction in any medium, provided the original work is properly cited.

\begin{abstract}
The objective of this study was to spatially analyze total trihalomethanes (TTHMs) and health risk associated with TTHMs in drinking water of different densely populated towns of Karachi city. Lifetime cancer risk and hazard index of THMs through oral ingestion and dermal absorption were calculated and mapped using kriging as an interpolation method to evaluate the carcinogenic and noncarcinogenic risk to human health in the study area. Lifetime cancer risk value due to the oral ingestion of TTHMs in different towns of the city was exceeded from $1.0 \times 10^{-6}$, showing that residents of these towns were expected to be at higher cancer risk. The hazard index for different towns was found to be lower than unity, indicating that no adverse health effects are expected as a result of exposure to THMs.
\end{abstract}

\section{Introduction}

Trihalomethanes (chloroform, bromodichloromethane, dibromochloromethane, and bromoform) constitute the major category of chlorinated disinfection byproducts (CDBPs), formed by the reaction between residual chlorine and natural organic matter $(\mathrm{NOM})$ in water.

Total trihalomethanes (TTHMs) are the sum of the mass concentrations of chloroform, bromodichloromethane, dibromochloromethane, and bromoform in $\mu \mathrm{g} \mathrm{L}^{-1}$. USEPA has established the maximum contaminant level for TTHMs at 80 parts per billion (ppb). THMs can be taken up through ingestion, skin absorption, and inhalation during drinking, showering, bathing, and swimming [1]. Lifetime exposure to trihalomethanes (THMs) may pose risks to human health [2]. Several epidemiologic studies have suggested a link between THMs exposure and risk of bladder, colon, and rectum cancers [3]. Jaundice, neurobehavioral effects, subjective central nervous system effect, and enlarged livers are the noncancer effects of THMs [4].

Human health risk assessment is an effective approach to quantitatively determine health risk posed by various contaminants $[5,6]$. Risk estimation is based on the computation of the upper bound excess lifetime cancer risk and noncarcinogenic hazards for multiple exposure pathways and receptors identified in the area of interest [7].

Geographical information system (GIS) has been shown to be a valuable tool for the spatial study of risk and hazard $[8,9]$. The implementation of risk models within GIS is a beneficial and realistic approach [10-13]. GIS and spatial interpolation methods such as kriging have been used in very few studies for the exposure assessment of THMs. Bove et al. [14] conducted a case control study of the geographic variability of exposure to THMs and risk for rectal cancer. Venkataraman and Uddameri [15] developed a system for the GIS-based evaluation of risks associated with THM exposure during showering in coastal Texas.

Evaluation of THMs and health risk assessment from exposure to THMs in drinking water of Karachi was previously reported $[16,17]$. The focus of the present study is on the spatial analysis of THMs and human health risk associated with THMs in different densely populated towns of Karachi city. This study demonstrates that a spatial analysis of THMs and human health risk evaluation can be helpful in the risk prediction, assessment of water quality, and in 


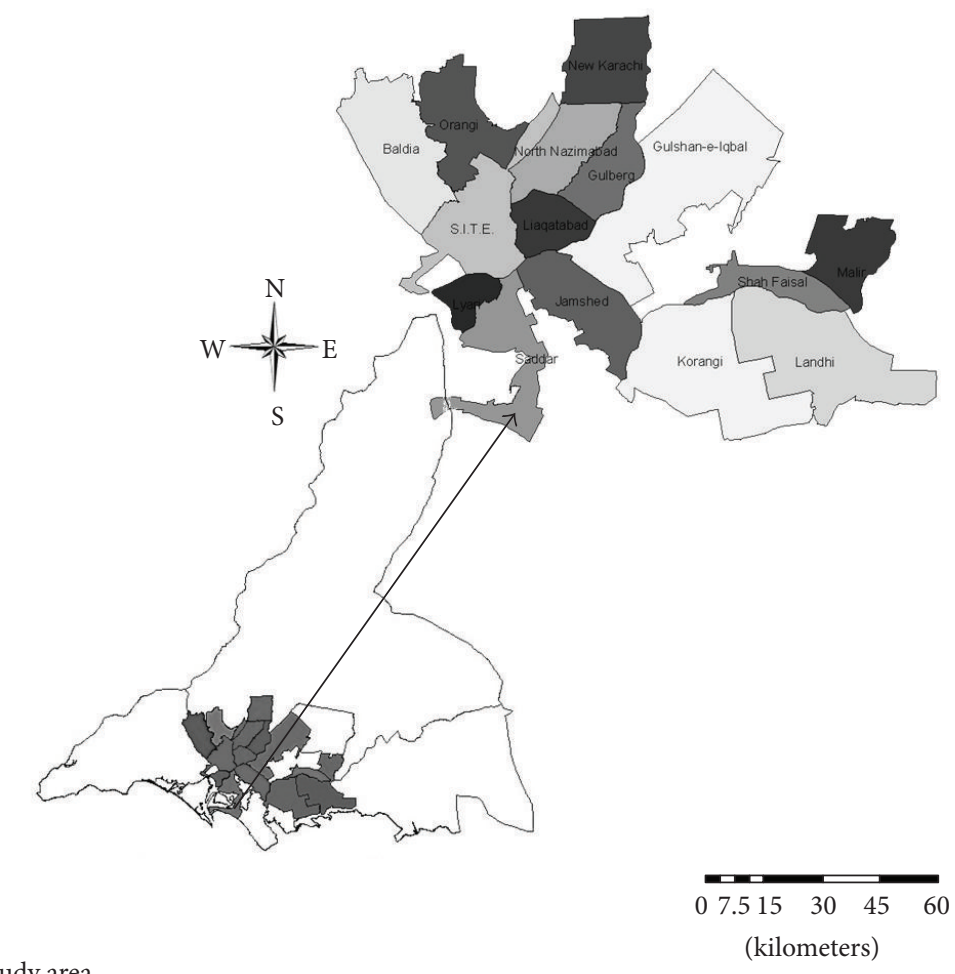

Study area

(kilometers)

Popultaion density $\left(1 / \mathrm{km}^{2}\right)$
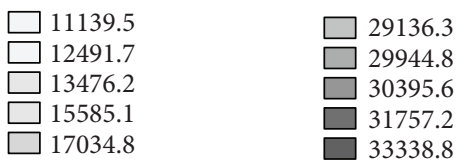

FIgURE 1: Map of sampling locations.

identifying suitable risk management strategies to minimize the health risk associated with THMs.

\section{Experimental Section}

Karachi, located at $24^{\circ} 45^{\prime}$ to $25^{\circ} 15^{\prime}$ north and $66^{\circ} 37^{\prime}$ to $67^{\circ} 37^{\prime}$ east, is the largest and the fastest growing megacity of Pakistan with a population of over 16 million. Karachi consists of 18 towns. 15 most thickly populated towns were selected for this study. Figure 1 presents a thematic map of selected towns of Karachi city and their population densities.

In Karachi, mostly people get their tap water from municipal water supply through a network of water distribution pipelines. Triplicate tap water samples were collected from 30 different locations in the area of interest, in March 2010. Water samples were preserved by using ascorbic acid as a residual chlorine quenching agent and stored at $4^{\circ} \mathrm{C}$ before analysis. A modification of EPA Method 551.1, which includes liquid-liquid extraction with methyl-tertbutyl ether (MTBE) [18], was adopted for the preparation of samples for gas chromatographic (GC) analysis [16]. Perkin Elmer Clarus 500 Gas Chromatograph equipped with an electron capture detector (ECD) was used for the determination of THMs (chloroform, bromodichloromethane, dibromochloromethane, and bromoform).

Carcinogenic risks of exposure to THMs levels were calculated [17] on the basis of USEPA methodology and other recently reported studies [19-22]. Oral ingestion and dermal absorption were considered as the two important ways for exposure to THMs. The cancer risks through ingestion route and dermal contact for each of the four THMs were calculated as the product of their chronic daily intake (CDI) and the potency or the slope factor $(\mathrm{SF})$, that is, CDI $\times \mathrm{SF}$ [17]. The chronic daily intake of each THM species through oral ingestion and dermal absorption were estimated as follows $[17,22,23]$ :

$$
\begin{gathered}
\mathrm{CDI}_{\text {oral }}=\frac{\mathrm{CW} \times \mathrm{IR} \times \mathrm{EF} \times \mathrm{ED}_{\text {oral }}}{\mathrm{BW} \times \mathrm{AT}} \\
\mathrm{CDI}_{\text {dermal }}=\frac{\mathrm{CW} \times \mathrm{SA} \times \mathrm{F} \times \mathrm{PC} \times \mathrm{ET} \times \mathrm{EF} \times \mathrm{ED}_{\text {dermal }} \times \mathrm{CF}}{\mathrm{BW} \times \mathrm{AT}},
\end{gathered}
$$

where CW the THM concentration $\left(\mu \mathrm{g} \mathrm{L}^{-1}\right)$, IR the ingestion rate $\left(\mathrm{Lday}^{-1}\right), \mathrm{EF}$ the exposure frequency (days year ${ }^{-1}$ ), $\mathrm{ED}$ the exposure duration (years), CF the conversion factor 


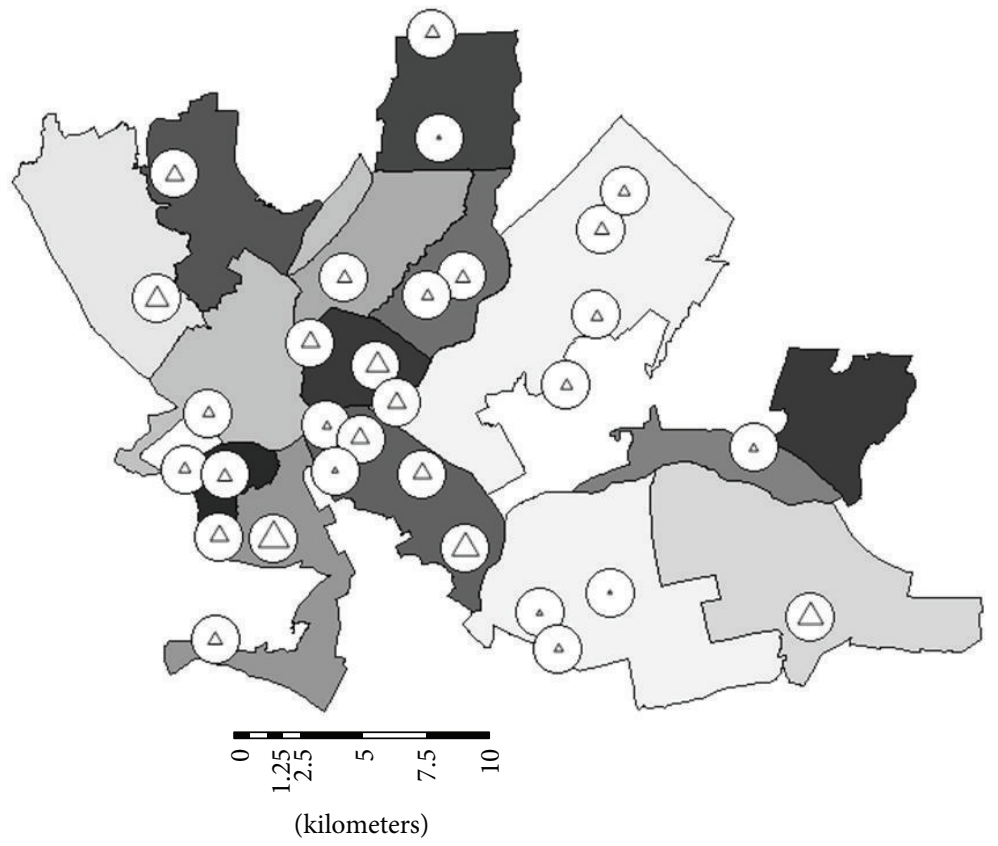

TTHMs $(\mu \mathrm{g} / \mathrm{L})$

- $0.640000-2.280000$

$\triangle$ 17.154001-27.700000

$\triangle \quad 2.280001-4.787000$

$\triangle 27.700001-49.100000$

$\triangle \quad 4.787001-8.830000$

$\triangle 49.100001-62.300000$

$\triangle 8.830001-10.370000$

$\triangle 62.300001-97.500000$

$\triangle 10.370001-17.154000$

$\triangle 97.500001-170.100000$

FIGURE 2: Spatial analysis of TTHM concentration.

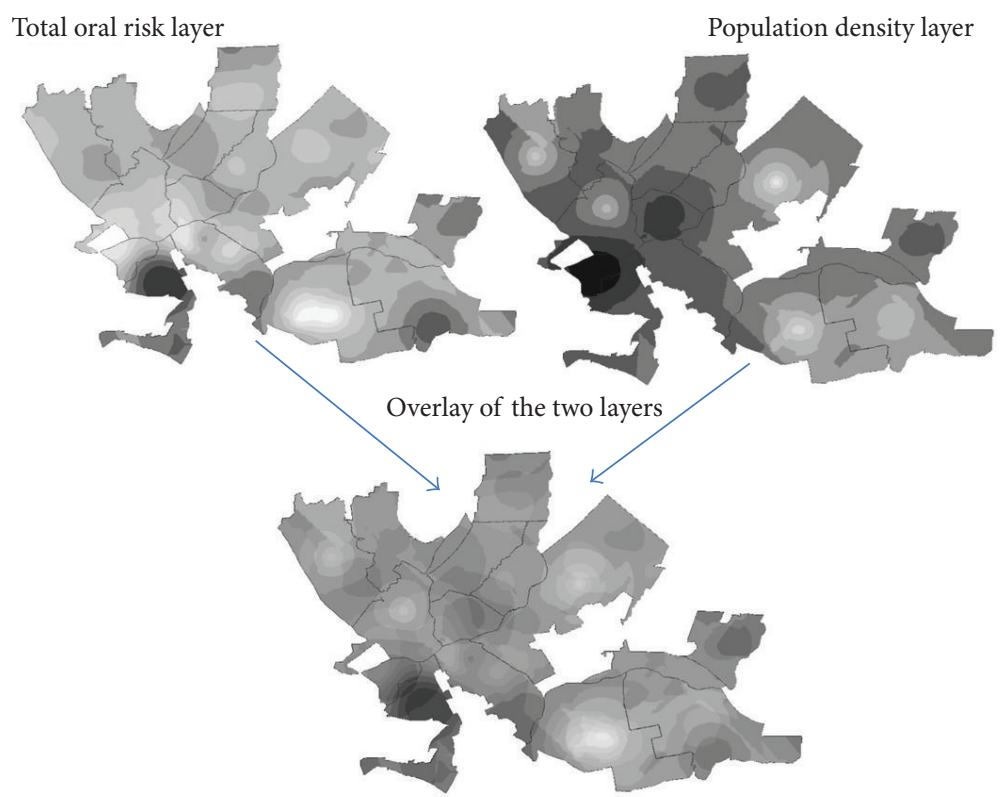

FIGURE 3: Overlay model of the study. 


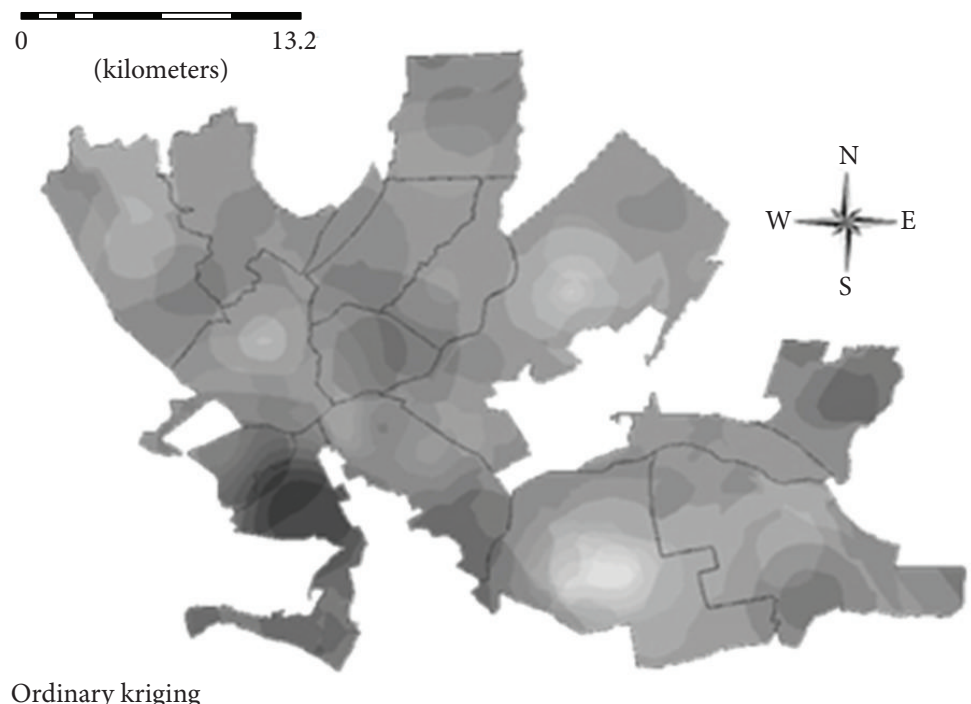

Ordinary kriging

Total oral risk

Fixed contours

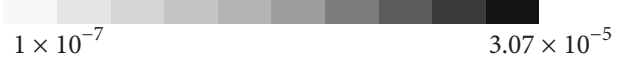

FIgURE 4: TTHM cancer risk via oral route.

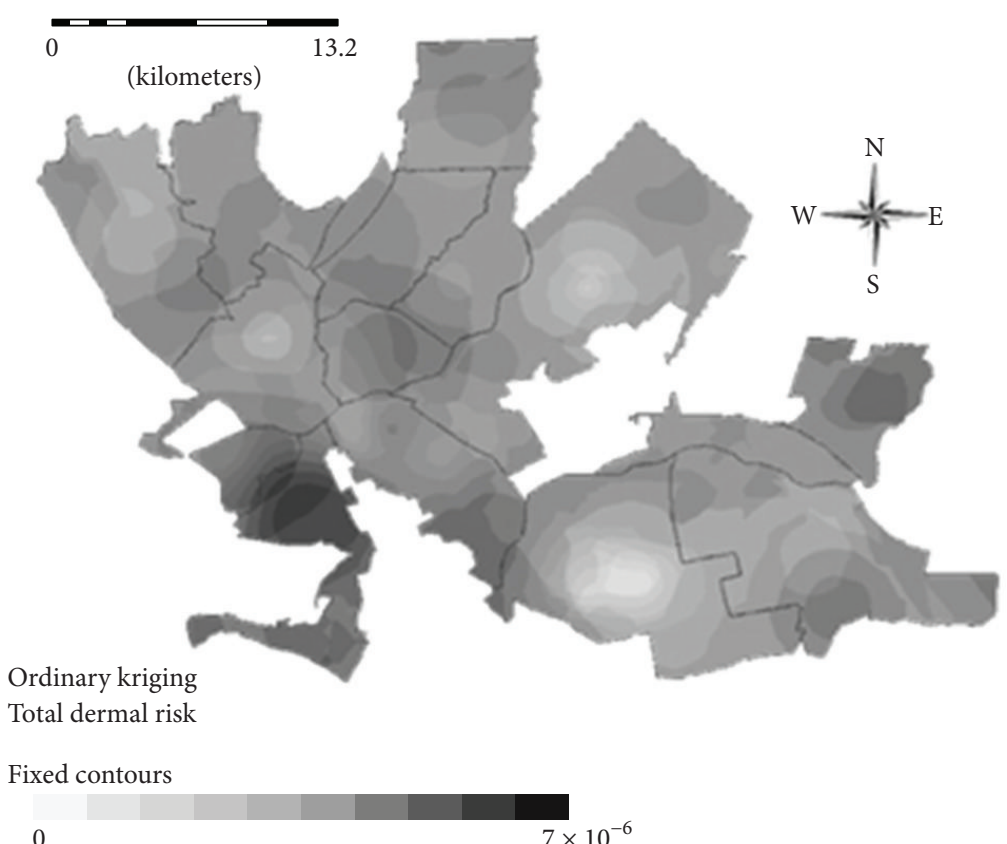

FIGURE 5: TTHM cancer risk via dermal exposure. 


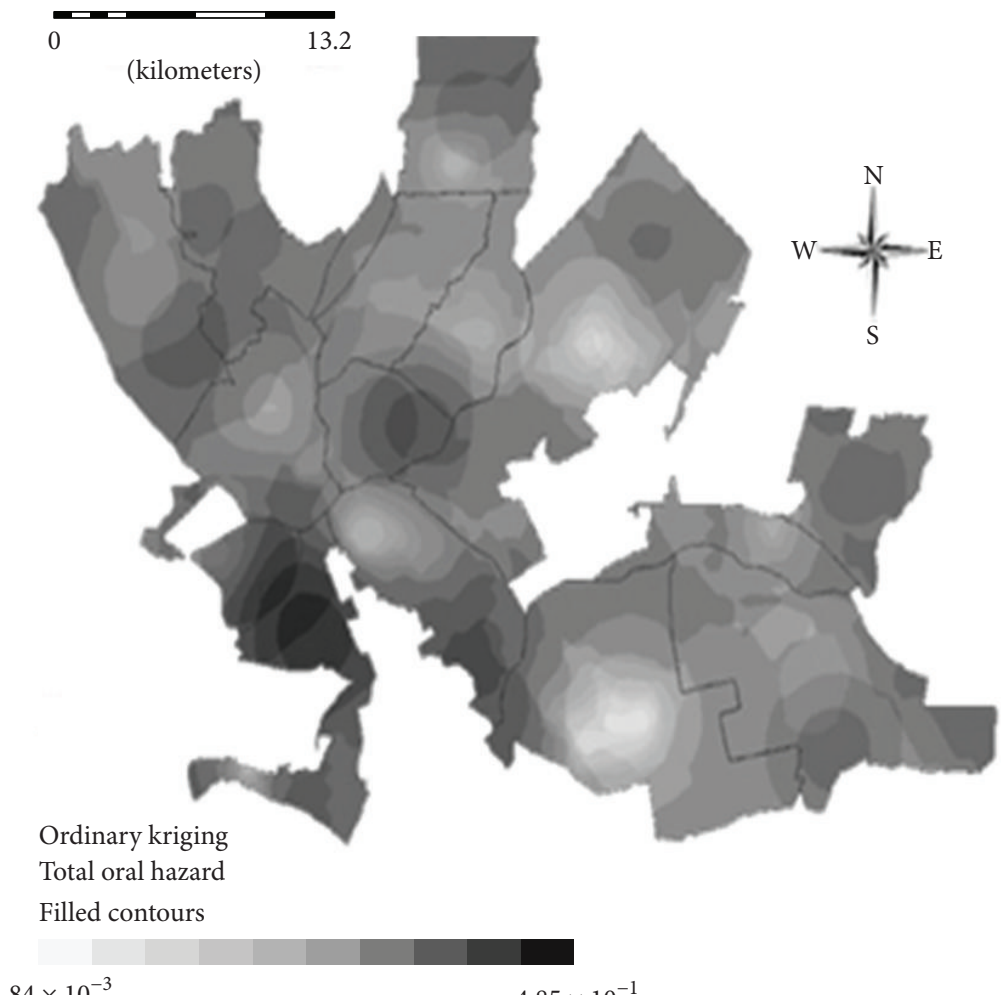

FIGURE 6: TTHM hazard index via oral route.

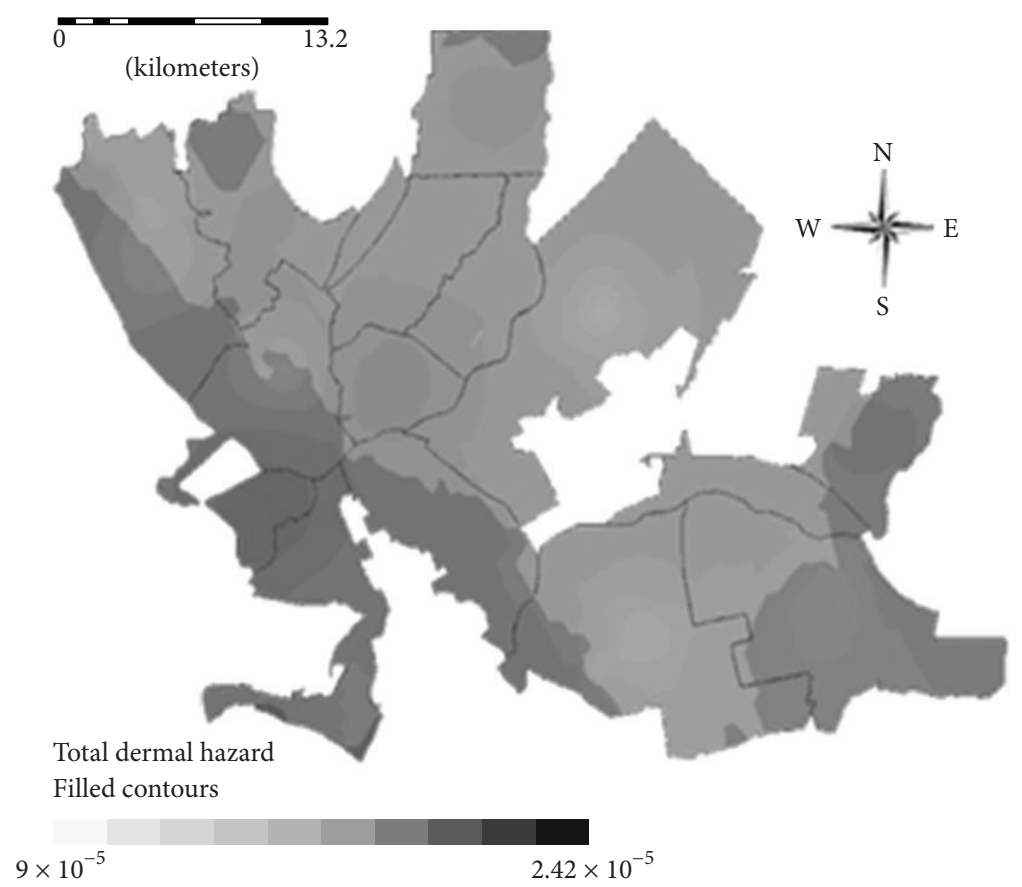

Figure 7: TTHM hazard index via dermal exposure. 
$\left(\mathrm{L} \mathrm{cm}^{-3}\right)$, BW the body weight $(\mathrm{kg})$, AT the average time (day), SA the skin-surface area available for contact $\left(\mathrm{m}^{2}\right)$, $\mathrm{F}$ is the fraction of skin in contact with water, PC the chemical specific dermal permeability constant $\left(\mathrm{cm} \mathrm{h}^{-1}\right)$, and ET the exposure time $\left(\mathrm{h} \mathrm{day}^{-1}\right)$. The values for the input parameters were taken from the literature $[20,22,24]$. The primary sources of the slope factors were Integrated Risk Information System (IRIS) and Risk Assessment Information System (RAIS) [20, 22]. For THM species, the USEPA range of concern is for an increased carcinogenic risk of $10^{-6}$, that is, $1: 1,000,000[25,26]$.

Total carcinogenic risks for each of the oral and dermal routes were calculated [17] as the sum of the risks values for four THMs specie, that is,

$$
\begin{aligned}
\text { total risk }= & \text { risk for chloroform } \\
& + \text { risk for bromodichloromethane } \\
& + \text { risk for dibromochloromethane } \\
& + \text { risk for bromoform. }
\end{aligned}
$$

For the noncarcinogenic risk assessment, the hazard indexes of TTHMs through different exposure routes were calculated as the ratio of CDI and reference dose (RfD) for THMs, that is, CDI/RfD $\mathrm{RHMs}_{\mathrm{TH}}$ [17]. The RfD values for THMs were taken from USEPA $[19,20,27]$. The greater the values of hazard index above unity, the greater is the level of concern [26].

The geographical locations (i.e., latitudinal/longitudinal positions) of the sampling sites were acquired during the sampling by a handheld GPS unit. Datasets including locations of sampling sites, the TTHMs levels in water samples determined through GC, and cancer risk and hazard index estimates associated with the these levels of TTHMs were imported into ArcView GIS software. A town map of Karachi was used as a base map of study area for spatial integration, surface interpolation, and development of thematic maps. Geostatistical Analyst was used to process the vector data (i.e., map layers of level of TTHMs in water samples and associated cancer risk and hazard index). Kriging is a method used for the interpolation of vector data.

\section{Results and Discussion}

Concentration of TTHMs in tap water samples at various locations of 15 different towns of the city is presented in Figure 2. High concentrations of THM were found in the tap water samples collected from Saddar, Lyari, Liaquatabad and Jamshed towns. In these high-density urban areas, a large number of individuals are therefore vulnerable to the resulting health risk.

Kriging method was used to interpolate and spatially link the risk and hazard data, utilizing sampling locations as point data source. To develop maps of risk and hazard, an overlay model was used. To make an overlay model of the present study, population density layer of the study area was made semitransparent and placed above risk layers for TTHM exposure via oral and dermal routes (Figure 3 ).
Figures 4 and 5 depict spatial variability of the lifetime cancer risk estimates for oral and dermal exposure to THMs, plotted via ordinary kriging interpolation in different towns of the city. In Lyari, Saddar, New Karachi, Baldia and Jamshed town and some areas of Landhi and Malir town, lifetime cancer risk value was exceeded from $1.0 \times 10^{-6}$ and therefore were expected to be at higher risk. Hazard index of TTHMs through oral and dermal exposure in different towns, using the ordinary kriging interpolation, is shown in Figures 6 and 7. The spatial patterns of $\mathrm{HI}$ for oral and dermal routes were found similar to those in cancer risk maps of the respective routes. However, hazard indexes in different towns did not indicate the noncancer effects of THMs.

Despite numerous studies has investigated the effects of THM exposure on human health worldwide, no categorical study has yet discussed the exposure of dense urban populations to the estimated risks of THMs in the present region. Therefore, the present study is one of the first studies in this region related to spatial analysis of human health risk associated with THMs in water. The findings of this study would be helpful for the concerned authorities to use GIS for the monitoring of THM concentration in tap water, identification of high risk areas, and for planning and devising strategies for controlling THM formation.

\section{Conclusion}

In conclusion, this work spatially analyzed total THM concentration and health risk associated with oral intake and absorption of THMs through skin in different densely populated towns of Karachi city. The residents of some towns were found to have a higher cancer risk through the oral ingestion of THMs. The hazard indexes of TTHMs in different towns were found to be lower than unity, which did not indicate the noncancer effects of THMs.

\section{Conflict of Interests}

The authors have declared no conflict of interests in this study.

\section{Acknowledgments}

This work was financially supported by the Dean Faculty of Science, University of Karachi. The author is thankful to the Pakistan Council of Scientific and Industrial Research (PCSIR), Karachi, for providing instrumental facilities for the measurement of THMs in the water samples. She also acknowledges the intellectual guidance of Dr. Salman Qureshi, Department of Geography, University of Karachi during this study.

\section{References}

[1] N. Iszatt, M. J. Nieuwenhuijsen, P. Nelson, P. Elliott, and M. B. Toledano, "Water consumption and use, trihalomethane exposure, and the risk of hypospadias," Pediatrics, vol. 127, no. 2, pp. e389-e397, 2011.

[2] S. Chowdhury, M. J. Rodriguez, and R. Sadiq, "Disinfection byproducts in Canadian provinces: associated cancer risks and 
medical expenses," Journal of Hazardous Materials, vol. 187, no. 1-3, pp. 574-584, 2011.

[3] K. P. Cantor, C. F. Lynch, M. E. Hildesheim et al., "Drinking water source and chlorination byproducts in Iowa. III. Risk of brain cancer," American Journal of Epidemiology, vol. 150, no. 6, pp. 552-560, 1999.

[4] R. B. Viana, R. M. Cavalcante, F. M. G. Braga et al., "Risk assessment of trihalomethanes from tap water in Fortaleza, Brazil," Environmental Monitoring and Assessment, vol. 151, no. $1-4$, pp. 317-325, 2009.

[5] Z. Karim, "Risk assessment of dissolved trace metals in drinking water of Karachi, Pakistan," Bulletin of Environmental Contamination and Toxicology, vol. 86, pp. 676-678, 2011.

[6] B. Wu, Y. Zhang, X. Zhang, and S. Cheng, "Health risk from exposure of organic pollutants through drinking water consumption in Nanjing, China," Bulletin of Environmental Contamination and Toxicology, vol. 84, pp. 46-50, 2010.

[7] P. Morra, S. Bagli, and G. Spadoni, "The analysis of human health risk with a detailed procedure operating in a GIS environment," Environment International, vol. 32, no. 4, pp. 444-454, 2006.

[8] F. J. Moral, P. Álvarez, and J. L. Canito, "Mapping and hazard assessment of atmospheric pollution in a medium sized urban area using the Rasch model and geostatistics techniques," Atmospheric Environment, vol. 40, no. 8, pp. 1408-1418, 2006.

[9] P. Goovaerts, "Geostatistical modelling of uncertainty in soil science," Geoderma, vol. 103, no. 1-2, pp. 3-26, 2001.

[10] L. Poggio and B. Vrščaj, "A GIS-based human health risk assessment for urban green space planning-an example from Grugliasco (Italy)," Science of the Total Environment, vol. 407, no. 23, pp. 5961-5970, 2009.

[11] A. Korre, S. Durucan, and A. Koutroumani, "Quantitativespatial assessment of the risks associated with high $\mathrm{Pb}$ loads in soils around Lavrio, Greece," Applied Geochemistry, vol. 17, no. 8, pp. 1029-1045, 2002.

[12] D. McGrath, C. Zhang, and O. T. Carton, "Geostatistical analyses and hazard assessment on soil lead in Silvermines area, Ireland," Environmental Pollution, vol. 127, no. 2, pp. 239-248, 2004.

[13] X. M. Liu, J. J. Wu, and J. M. Xu, "Characterizing the risk assessment of heavy metals and sampling uncertainty analysis in paddy field by geostatistics and GIS," Environmental Pollution, vol. 141, pp. 257-264, 2006.

[14] G. E. Bove, P. A. Rogerson, and J. E. Vena, "Case control study of the geographic variability of exposure to disinfectant byproducts and risk for rectal cancer," International Journal of Health Geographics, vol. 6, article 18, 2007.

[15] K. Venkataraman and V. Uddameri, "A GIS-based evaluation of risks due to trihalomethane exposure during showering in coastal Texas," Clean Technologies and Environmental Policy, vol. 14, pp. 551-564, 2012.

[16] Z. Karim, M. Mumtaz, and T. Kamal, "Evaluation of trihalomethanes in tap water samples of Karachi City (Pakistan)," Journal of Basic and Applied Sciences, vol. 7, pp. 7-10, 2011.

[17] Z. Karim, M. Mumtaz, and T. Kamal, "Health risk assessment of trihalomethanes from tap water in Karachi, Pakistan," Journal of the Chemical Society of Pakistan, vol. 33, pp. 215-219, 2011.

[18] A. D. Nikolaou, T. D. Lekkas, S. K. Golfinopoulos, and M. N. Kostopoulou, "Application of different analytical methods for determination of volatile chlorination by-products in drinking water," Talanta, vol. 56, no. 4, pp. 717-726, 2002.
[19] M. Basu, S. K. Gupta, G. Singh, and U. Mukhopadhyay, "Multiroute risk assessment from trihalomethanes in drinking water supplies," Environmental Monitoring and Assessment, vol. 178, pp. 121-134, 2011.

[20] S. C. Lee, H. Guo, S. M. J. Lam, and S. L. A. Lau, "Multipathway risk assessment on disinfection by-products of drinking water in Hong Kong," Environmental Research, vol. 94, no. 1, pp. 47-56, 2004.

[21] V. Uyak, "Multi-pathway risk assessment of trihalomethanes exposure in Istanbul drinking water supplies," Environment International, vol. 32, no. 1, pp. 12-21, 2006.

[22] G. S. Wang, Y. C. Deng, and T. F. Lin, "Cancer risk assessment from trihalomethanes in drinking water," Science of the Total Environment, vol. 387, no. 1-3, pp. 86-95, 2007.

[23] A. R. Pardakhti, G. R. N. Bidhendi, A. Torabian, A. Karbassi, and M. Yunesian, "Comparative cancer risk assessment of THMs in drinking water from well water sources and surface water sources," Environmental Monitoring and Assessment, vol. 179, no. 1-4, pp. 499-507, 2011.

[24] RAIS (Risk Assessment Information System), 2005, http:// rais.ornl.gov/.

[25] USEPA (US Environmental Protection Agency), "Draft final guidelines for carcinogen risk assessment," Risk Assessment Forum EPA/630/P-03/001A, NCEA-F-0644A, 2003.

[26] D. R. Rowe and I. M. Abdel-Magid, Handbook of Wastewater Reclamation and Reuse, CRC Press, 1995.

[27] USEPA (US Environmental Protection Agency), "Guidelines for carcinogen risk assessment," Risk Assessment Forum NCEA-F0644, 1999. 

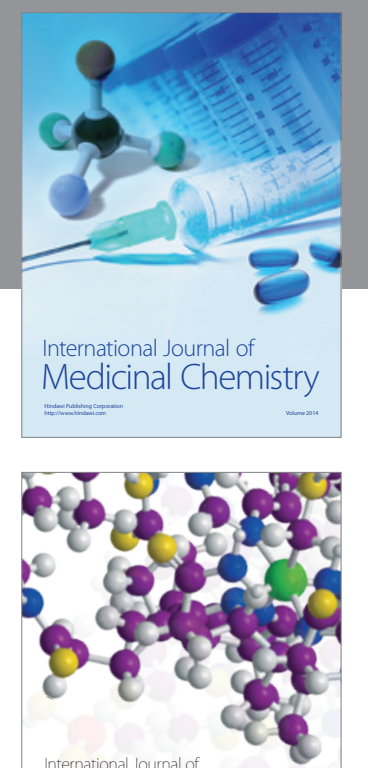

\section{Carbohydrate} Chemistry

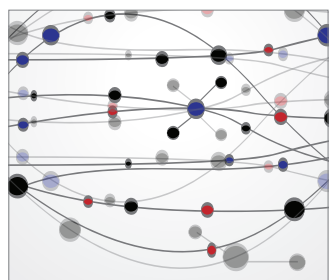

The Scientific World Journal
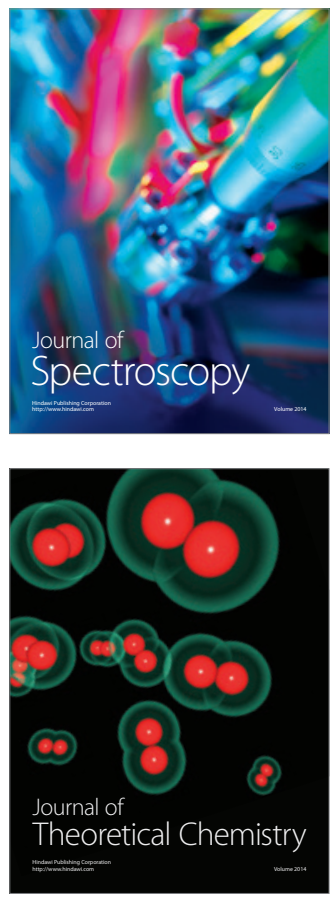
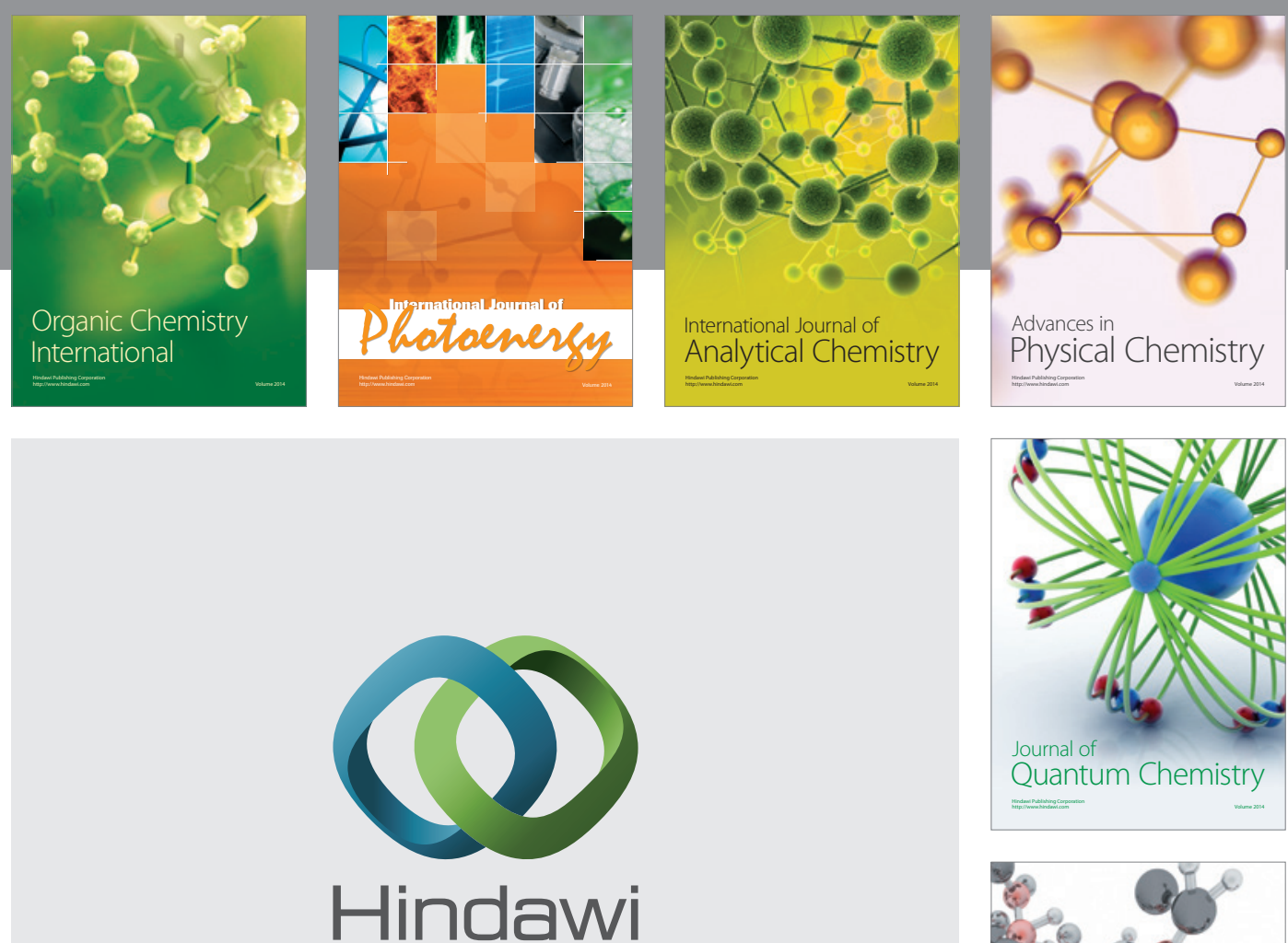

Submit your manuscripts at

http://www.hindawi.com

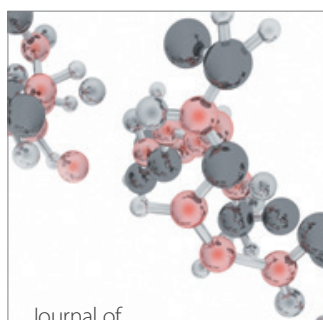

Analytical Methods

in Chemistry

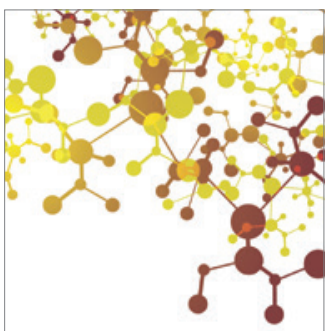

Journal of

Applied Chemistry

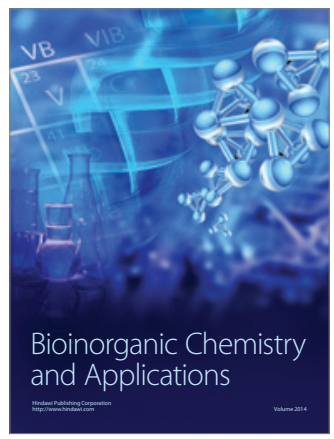

Inorganic Chemistry
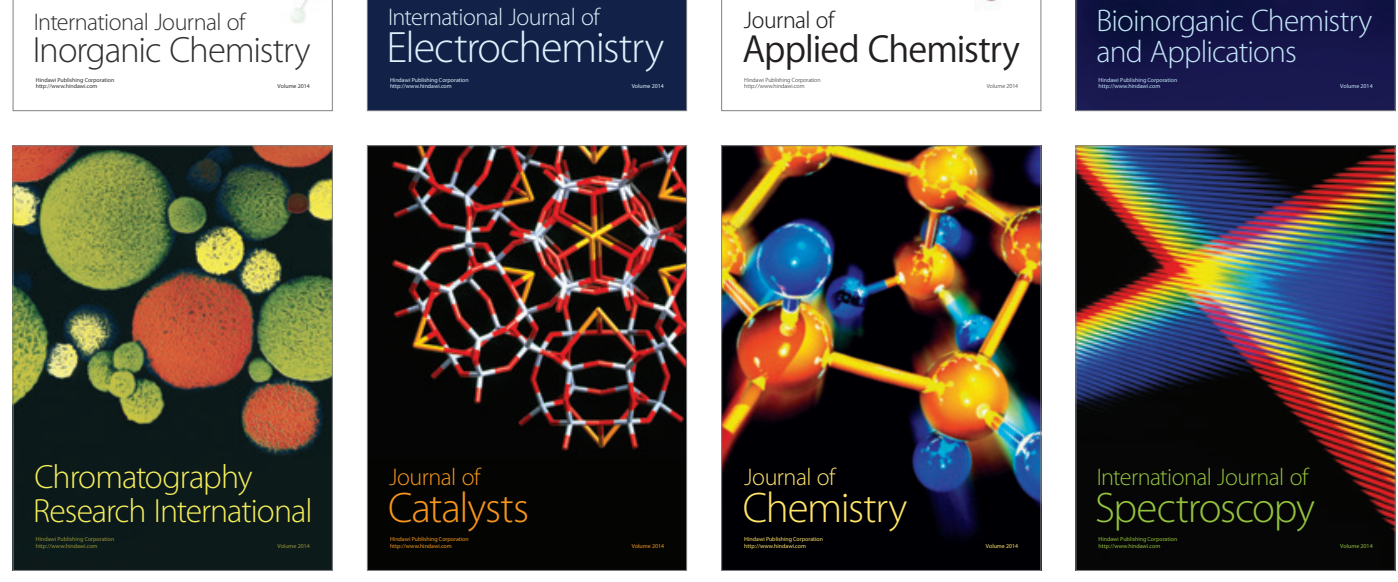